\title{
O PROCESSO DE FORMAÇÃO DE TUTORES DOS CURSOS DE GRADUAÇÃO NA MODALIDADE A DISTÂNCIA: RECORTES DE EXPERIÊNCIA
}

CANOAS/RS JULHO/2018

\author{
Michele de Mattos Kreme - UniLaSalle - michele.kreme@unilasalle.edu.br \\ Ana Margô Mantovani - UniLaSalle - ana.mantovani@unilasalle.edu.br
}

Tipo: Relato de Experiência Inovadora (EI)

Categoria: Métodos e Tecnologias

Setor Educacional: EDUCAÇÃO SUPERIOR

\begin{abstract}
RESUMO
Este artigo apresenta uma reflexão acerca dos processos de formação continuada de tutores para promover o desenvolvimento da fluência tecnológica digital e pedagógica necessária para atuação na tutoria online de um percurso de formação continuada. A partir de uma pesquisa qualitativa em andamento, caracterizada em um estudo de caso, buscamos compreender quais são as percepções dos tutores dos cursos de graduação, na modalidade a distância, de uma instituição de ensino superior, em relação à apropriação das Tecnologias Digitais (TD) no contexto da cibercultura.

Nesse cenário, entendemos que os processos de formação continuada de tutores precisam incluir, além de aplicações das TD nas práticas pedagógicas, reflexões a respeito dos impactos dessas TD nos processos de ensinar e aprender na contemporaneidade.
\end{abstract}

Palavras-chave: Educação a distância. Formação Continuada. Tecnologias Digitais Tutoria.

\section{AGRADECIMENTOS}

AGRADEÇO AOS MEUS ORIENTADORES PROF. DOUTOR CLEDES CASAGRANDE E PROFa DOUTORA ANA MARGÔ MANTOVANI, PELO MODO COMO ME APOIAM NESTA INVESTIGAÇÃO, COM UMA ORIENTAÇÃO CIENTÍFICA CRITERIOSA E EFETIVA. 


\section{Introdução}

A Educação a Distância (EaD) se caracteriza como uma modalidade educacional na qual a mediação dos atores envolvidos nos processos de ensino e aprendizagem, dispersos geograficamente, ocorre com a utilização de Tecnologias Digitais. Desse modo, a importância da EAD torna-se cada vez mais evidente e relevante à medida em que consegue atingir diferentes regiões e camadas da população que buscam educar-se ou atualizar-se profissionalmente, possibilitando a flexibilidade de tempo e lugar. Nesse cenário, entendemos que o processo formativo desses atores, quer sejam professores ou tutores, ainda suscita reflexões e investigações que possam contribuir para a qualificação desse processo.

A revolução trazida pelos meios de comunicação e principalmente, pela internet, possibilita o acesso à informação de maneira cada vez mais rápida. É visível a grande evolução das novas tecnologias que a cada instante vem se transformando e renovando. Vivenciamos um avanço tecnológico de notáveis proporções que facilita a disseminação do conhecimento e contribui para que a informação ocorra de modo acelerado e eficiente. Desta forma, mediada pela intervenção tecnológica, a Internet e os seus serviços associados, bem como as TD têm sido determinantes nestas transformações, enquanto processo inovador e capaz de estabelecer novas modalidades de ensino e de aprendizagem.

Assim, observamos a influência das TD em nossa rotina diária nos diversos contextos em que estamos inseridos e em particular nos processos educacionais é parte desse processo e legitima a demanda da Educação a Distância, que surge neste contexto como uma modalidade fundamental de promoção de oportunidades e diminuição destas distâncias. Entendemos que este cenário advindo da sociedade do conhecimento e suas novas demandas educacionais, requer um novo perfil de profissional, que deverá estar em constante aprendizado.

Os sistemas educacionais sofrem constantes mudanças para atender estas demandas, desta forma, observa-se o aumento gradativo da necessidade por cursos tanto de formação inicial quanto superior. Desta forma, considerando que a atual evolução cultural tem proporcionado mudanças nas relações sociais e culturais, novos conceitos foram integrados em nosso cotidiano, sendo um deles a cibercultura, que se manifesta a partir da sinergia presente entre a sociabilidade que a grande rede nos proporciona e o desenvolvimento dos mecanismos das TD.

\section{Evolução das Tecnologias Digitais}


O surgimento de novas tecnologias está presente no cotidiano da sociedade contemporânea. A evolução tecnológica do mundo atual resulta em impactos em nossa forma de relacionamento com os outros e com os conhecimentos. Os avanços tecnológicos proporcionaram possibilidade de novos meios de comunicação e novas formas de conseguir e trocar informações, permitindo que os indivíduos se comuniquem de qualquer lugar do mundo. Assim, as tecnologias emergentes na sociedade contemporânea permitem que a percepção de espaço e tempo do indivíduo proporcionem novas concepções.

É nesse espaço que se configuram as relações interpessoais fundamentais no processo de construção do conhecimento. Segundo Lemos, "a cultura contemporânea, associada às tecnologias digitais (ciberespaço, simulação, tempo real, processos de virtualização, etc.), vai criar uma nova relação entre a técnica e a vida social que chamaremos de cibercultura" (LEMOS, 2004, p. 15). Para o autor, a Cibercultura, pode ser entendida também como Cultura Digital, é uma forma sociocultural que modifica hábitos sociais, práticas de consumo cultural, ritmo de produção e distribuição da informação, criando novas relações no trabalho e no lazer, novas formas de sociabilidade e de comunicação social a partir do desenvolvimento e uso das Tecnologias Digitais. Nesse sentido, Lemos (2004) ainda afirma que o ciberespaço cria condições de desterritorializações sob os aspectos político, econômico, cultural e subjetivo, como também possibilita reterritorializações por meio de redes comunitárias formadas na internet.

Para Castells (1999) o ciberespaço é definido como o espaço de fluxos, onde a infraestrutura tecnológica constrói a rede e define as regiões econômicas e as regras de mercado. Ele ainda complementa afirmando que a rede de comunicação é a forma espacial: os lugares não desaparecem, mas a sua lógica e o seu significado são absorvidos na rede. A rede apresenta um espaço virtual e imaterial de novas relações, por onde circulam fluxos eletrônicos de dados, como um âmbito desterritorializado de bases cooperativas, de trocas interativas, de acessos instantâneos e uma multiplicidade infinita de saberes, conhecido como ciberespaço (SANTOS, 2010, p. 2).

Sabemos que as TD estão presentes no cotidiano de grande parte da população mundial e, de acordo com Lévy (1999), estão entrelaçadas entre o ser humano e o mundo material no qual habitam, tornando, portanto, impossível separá-los. Assim a nossa sociedade contemporânea experiência um fenômeno em que espaço e tempo deixaram de ter o mesmo significado de algumas décadas atrás. Entretanto, o tempo atual é marcado pela mistura de todas as formas de cultura, inclusive das formações culturais (oral e escrita) anteriores ao aparecimento dessas gerações tecnológicas, de modo que todas elas estão hoje interconectadas (SANTAELLA, 2003). Portanto, as TD 
proporcionaram um novo sentido com novos hábitos e novas necessidades. Desta forma, a maneira como as pessoas vivem tem sido influenciada por essas tecnologias; logo, estas devem integrar-se à formação pessoal e social dos atores envolvidos nos processos de ensino e aprendizagem da sociedade contemporânea.

\section{A formação de tutores no contexto da cibercultura}

A chegada do século XXI trouxe a necessidade de se refletir e redefinir muitos aspectos até então considerados incontestáveis, como por exemplo, o fato de que apenas a graduação não é suficiente para tornar o indivíduo apto para atuar na sua área profissional o resto da vida. Por sua vez, a educação vem passando por um período de transformações e construções, isso devido ao impacto das TD nos processos de ensino e aprendizagem. Assim, a EAD está em plena expansão e os profissionais envolvidos neste processo precisam buscar formação para acompanhar a evolução das TD e das metodologias de ensino.

A partir desta percepção, torna-se essencial uma renovação do saber fazer educativo, não somente ao que diz respeito à atualização em relação aos conhecimentos específicos das áreas de atuação, mas também pela melhoria na qualidade do ensino que oferecemos. As modificações advindas do processo de globalização, fenômeno que gera acesso dinâmico e irreversível às informações e interações entre culturas, é algo já instalado e que não pode ser deixado de lado ou ignorado por nós. Diante disso, o tutor precisa ter consciência de que sua formação deve ser permanente e integrada no seu dia-a-dia. Partindo desta reflexão, observa-se o quanto o tutor desempenha um papel imprescindível no processo da EAD, e que, portanto, precisa ser um profissional apto e capacitado para atender as necessidades dos alunos, alcançando os objetivos propostos pelo curso e pela Instituição de Educação Superior (IES), assim como as suas próprias expectativas profissionais como tutor.

Concordamos com Nóvoa (1997) quando aponta que a formação de professores necessita despertar uma perspectiva crítico-reflexiva, que forneça aos próprios professores os meios de um pensamento autônomo e que facilite as mudanças de autoformação participada de sua prática, em um movimento de reflexão-ação. Entendemos que a formação dos tutores também ocorre nessa perspectiva apontada por Nóvoa e, portanto, é uma formação constituída por uma diversidade de processos e saberes oriundos dos campos da formação pessoal e profissional, dos saberes disciplinares e curriculares, da experiência, considerando os múltiplos espaços do conhecimento, que mobilizam saberes plurais. 
Entretanto, a formação continuada não pode ser idealizada como um simples processo de acumulação de conhecimentos, mas sim, como um trabalho de flexibilidade crítica sobre as práticas de construção permanente da identidade pessoal e profissional. Esta formação poderá contribuir na superação de dificuldades ou lacunas na prática docente e também da tutoria que pressupõe qualificação por meios decorrentes de novos saberes.

Segundo Meirieu (2006), a autoformação é autorreflexiva, é um processo que acontece no sujeito, é inalienável, é condição de base para a aquisição de aprendizagens e condutas que ninguém consegue fazer pelo outro. A reflexão, nesse caso, identifica-se com os processos em que o tutor está disposto à reflexão autocrítica e criatividade, que exigem transformação em contraposição à tendência de ficar acomodado em sua "zona de conforto".

A partir destas perspectivas, podemos considerar que a reflexividade do tutor precisa estar instigada pela conscientização teórica e crítica sobre a realidade em que está inserido, considerando, além da reflexão sobre sua prática, também sobre os distintos cenários sociais, políticas e institucionais em que acontecem as práticas educativas. Esta ação de rever, pensar e ressignificar, proporciona ao tutor transformar ideias e atitudes sobre os processos de ensino e aprendizagem, assim como permite que ele possa descobrir novos caminhos para o aperfeiçoamento das práticas de tutoria e a descoberta de novos rumos na sua ação.

\section{Fluência tecnológica digital e pedagógica do tutor}

A ação do tutor acontece na mediação das diversas situações de aprendizagem planejadas, geralmente, pelo professor. Cabe destacar que, cada IES que oferta cursos na modalidade a distância designa o papel do tutor com características distintas, definidas a partir das concepções epistemológicas que norteiam o projeto pedagógico de EaD da própria IES. Assim, o tutor tanto pode exercer o papel de docente quanto de apoio à docência e fazer parte do corpo técnico administrativo e/do quadro de docentes. Contudo, independente deste perfil definido por cada IES, compreende-se ser necessário para uma melhor prática da tutoria desenvolver e aprimorar a fluência tecnológica digital e pedagógica.

De acordo com Schneider (2017), a fluência tecnológica digital constitui-se pelo conhecimento das habilidades contemporâneas, conceitos fundamentais e capacidades cognitivas do professor nas etapas de planejamento e implementação de atividades de EaD. Entendemos que a fluência pedagógica está articulada com a tecnológica digital, 
no entanto envolve competências necessárias para a ação didático-pedagógica que ocorre na mediação das interações dos estudantes tanto no Ambiente Virtual de Aprendizagem (AVA), quanto nos encontros presencias, neste caso, quando a modalidade é híbrida.

Considerando que a fluência tecnológica digital é indispensável à prática de tutoria em ambientes informatizados, Schneider (2011) destaca que "ser fluente tecnologicamente significa conhecer e apropriar-se das ferramentas educacionais, seus princípios e aplicabilidade em diferentes situações".

A concepção de alguns autores, tais como NÓVOA, SCHNEIDER e SANTOS, referidos no artigo abrange uma visão do tutor como um indivíduo reflexivo que pensa sobre a sua práxis e também instiga o estudante a pensar sobre sua ação, que produz, orienta, realiza a mediação pedagógica e constrói conhecimento de forma colaborativa e cooperativa. Considerando os referenciais teóricos aqui referidos, podemos apontar, sucintamente algumas funções dos tutores, tais como: ter fluência tecnológica digital e pedagógica, se apropriar do Ambiente Virtual de Aprendizagem (AVA), organizar os materiais didáticos, problematizar e esclarecer as dúvidas sobre o conteúdo abordado, comentar as produções, instigar a discussão, acompanhar o processo de aprendizagem e de avaliação dos estudantes.

Este cenário remete a necessidade de reconfigurações e formação para a aplicação de diferentes TD utilizadas nesse contexto. $\mathrm{Na}$ área da educação, as diversas TD e uma diversidade de opções metodológicas (tais como metodologias ativas, sala de aula invertida, projetos baseados na resolução de problemas, estudos de caso, entre outras) podem intervir na prática educativa em todos os níveis e áreas de ensino. Diante disso, o tutor precisa estar consciente de que sua formação necessita ser permanente e integrada a sua rotina, pois além de competências e habilidades para utilização das TD, estas constantes mudanças apontam necessidades de formação para atuação na modalidade a distância, o que consequentemente poderá significar melhoria da qualidade dos cursos ofertados nessa modalidade.

Partindo dessas reflexões, entendemos como papel primordial do tutor a mediação entre o estudante e os conhecimentos que estão sendo estruturados, considerando o planejamento das estratégias de ensino e a organização didático-pedagógica no AVA, bem como a utilização de diversas TD que possibilitam os processos de colaboração e cooperação. Nesse escopo, também é fundamental o papel de incentivador, facilitador para que os alunos pensem de forma autônoma e crítica, compreendendo que toda a socialização de experiência é um processo de formação mútua, entre estudante e tutor. 
Neste sentido, entende-se que a atuação do tutor também perpassa por sua habilidade de relacionar-se, considerando sua função de interagir, orientar, motivar e construir com o aluno sua trilha de aprendizagem, esclarecendo dúvidas, contribuindo com seu processo de significação e compartilhando experiências.

5. Recortes das percepções dos tutores acerca das TD: considerações finais

A EAD envolve processos complexos e, para que tenha qualidade, precisa ser pensada a partir das concepções epistemológicas proposta pedagógica até a sua prática no cotidiano. Observamos que um dos maiores desafios desta modalidade é sair de uma aula linear, passiva e individual, com modelos de conteúdos feitos para assimilar e repetir, tendo o tutor como único detentor do conhecimento e responsável pelo processo educacional.

Assim, considerando o cenário atual dessa sociedade em rede, é possível inferir que as inovações tecnológicas, promoveram e continuam promovendo consideráveis mudanças no cotidiano dos indivíduos e consequentemente emergem novas formas de aprender, de conviver, de se relacionar com outras pessoas e com o conhecimento. Ou seja, no contexto da cibercultura aprende-se a reaprender, a conhecer, a comunicar-se, a ensinar, a interagir de diversas formas, nos diferentes espaços (geográficos e online) e grupos. Por isso o processo de formação de tutores precisa ser acompanhado por discussões relacionadas à sua prática, à reflexão sobre sua atuação e a atualização constantes.

Diante deste contexto, entendemos que a fluência tecnológica digital e pedagógica relaciona-se ao conhecimento e a mobilização de competências que vão além da utilização das TD. Ou seja, para desenvolver e aprimorar a fluência tecnológica digital e pedagógica no exercício da tutoria em cursos mediados por TD, torna-se fundamental que o tutor desenvolva competências que viabilizem a interação e mediação de práticas pedagógicas inovadoras, em congruência com essas tecnologias.

Os resultados obtidos através das entrevistas com os tutores foram coletadas no ambiente virtual de aprendizagem, demonstraram que o curso de formação auxiliou no preparo dos futuros tutores para uma adequada atuação no curso de Tecnologias. Apresentamos, a seguir, recortes das percepções destes tutores acerca da importância do uso das TD na tutoria online. Estes tutores (40 tutores, sendo 20 da área de Gestão e Negócios e 20 da área da Educação) participaram de uma formação continuada, incialmente realizada de forma presencial, mas com continuidade por meio do AVA, em uma IES da rede privada. Os depoimentos foram coletados por meio das interações dos 
tutores em um fórum temático proposto no AVA.Percebemos que, grande parte dos tutores participantes da formação referida, considera que o uso TD pode contribuir para auxiliar os estudantes no desenvolvimento das atividades propostas, conforme evidencia a narrativa da tutora (aqui denominada de T1).

"As TD são recursos que facilitam o desenvolvimento das atividades propostas no AVA , bem como a comunicação com os estudantes. " (Tutora T1).

"Auxiliam os estudantes com metodologias que ampliam a capacidade de raciocínio, e possibilitam a construção do conhecimento de forma colaborativa e cooperativa." (Tutora T2).

"Através do uso de TD poderão ser elaboradas diferentes atividades que permitam que os estudantes conheçam novas TD, tornando o aprendizado mais interativo e flexível, gerando maior conhecimento." (Tutora T3).

"A partir do momento que me apropriei dessas tecnologias eu tenho consciência que preciso utilizá-las em minha pratica pedagógica e também para promover a mediação do estudante da EaD e colaborar com a sua formação, auxiliando-o quando não souber utilizar as TD." (Tutor T5).

Diante dos comentários pode?se perceber que o curso preparou os tutores e possibilitou o desenvolvimento de competências que contribuírão na atuação dos mesmos como tutores e mediadores da aprendizagem através da educação à distância. Além disso, as narrativas apresentadas demonstram as percepções dos tutores a respeito da relevância do uso das TD nas práticas da tutoria online. Evidenciamos que os tutores compreendem que o uso de diferentes TD proporcionam práticas pedagógicas inovadoras, que podem contribuir para resultados diferenciados, promovendo condições favoráveis para aprendizagem. Também acenam para a importância da mediação pedagógica nesse contexto e percebem como as TD podem promover diferentes formas de mediação. Desta forma, compete ao tutor desenvolver a fluência tecnológica digital e pedagógica para ressignificar os processos de tutoria online, tornando-se mais próximo dos estudantes e com condições favoráveis de auxiliá-lo em seu percurso de aprendizagem.

O estudo realizado deixa espaço para outras reflexões. Entretanto, nesse cenário, entendemos que os processos de formação continuada de tutores precisam incluir, além de aplicações das TD nas práticas pedagógicas, reflexões a respeito dos impactos dessas TD nos processos de ensinar e aprender na contemporaneidade. 


\section{REFERÊNCIAS}

CASTELLS, M. A sociedade em rede: a era da informação: economia, sociedade e cultura. São Paulo: Paz e Terra, 1999. v.1.

LEMOS, André. Cibercultura: tecnologia e vida social na cultura contemporânea. 2 ed. Porto Alegre: Sulina, 2004.

LEMOS, André; LÉVY, Pierre. O futuro da internet: em direção a uma ciberdemocracia planetária. 4 ed. São Paulo: Paulus, 2010.

LÉVY, Pierre. A inteligência coletiva: por uma antropologia do ciberespaço. 3 ed. São Paulo: Loyola, 2000.

MEIRIEU, P. Carta a um jovem professor. Porto Alegre: Artmed, 2006.

NÓVOA, Antonio. Os Professores e suas Formações. 11.ed. Lisboa: Dom Quixote, 1997.

NÓVOA, A. Formação de professores e profissão docente. In: NÓVOA, A. (Org) Os professores e sua formação. Lisboa: Publicações Dom Quixote, 1997.

SANTAELLA, L. A crítica das mídias na entrada do século XXI. In: PRADO, J. L. A. (org.). Crítica das práticas midiáticas: da sociedade de massa às ciberculturas. São Paulo: Hackers Editores, 2002.

SANTOS, Edméa. Pesquisa - Formação na Cibercultura. Santo Tirso: 2014.

SANTOS, Edméa. Educação online para além da EaD: um fenômeno da cibercultura. In: SILVA, Marco et al (orgs.). Educação on-line: cenário, formação e questões didáticometodológicos. Rio de Janeiro: Walk, 2010.

SCHNEIDER, D. R. Prática Dialógico-Problematizadora dos Tutores na UAB/UFSM: Fluência Tecnológica no Moodle. Santa Maria: Universidade Federal de Santa Maria, 2011. 185f. Dissertação de Mestrado. 